\title{
Workshop Explores Synergies Between Nanotechnology and Nuclear Science
}

\author{
Lynne Robinson
}

In the wake of the pioneering days

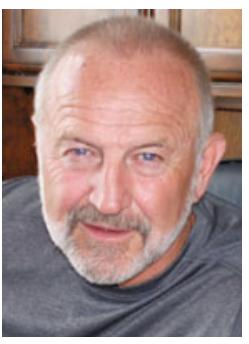

Steve Winston

of the Manhattan Project, research and development in nuclear technology has progressed rather incrementally. The pace has been governed by a myriad of

factors unique to the industry: the large-scale consequences of accidents and failures; a federal regulatory process focused on safety and proven technology; the extreme operating environments associated with fission and fusion; the need for large, complex facilities along with specialized knowledge and equipment; the nature of large-scale demonstrations requiring significant investments of resources and time; and the imperative to maintain security over materials and information. The 2011 disaster at the Fukushima Daiichi Nuclear Power Station in Japan has only served to underscore the complexities of moving nuclear science forward while effectively addressing the risks inherent in its implementation.

A possible avenue to accelerated development of a safer and more effective generation of nuclear technologies could be a realm of science born more than half a century after the dawn of the nuclear age. "Nanotechnology's amazing properties and revolutionary breakthroughs could potentially be a catalyst for a corresponding revolution in nuclear technology," said Steve Winston, Winston \& Associates.
"The orders of magnitude improvements that nanotechnology offers in strength of materials, thermal conductivity, lubricity, electrical conductivity, corrosion resistance, and every other imaginable parameter have literally reinvented whole industries with no end in sight."

Since this potentially fruitful intersection of nanoscience and nuclear

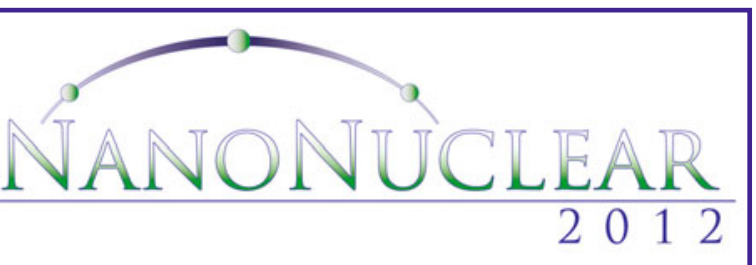

technology has only been explored on a limited basis to date, TMS, in conjunction with the U.S. Department of Energy (DOE) Office of Nuclear Energy, sponsored the 2012 NanoNuclear Workshop in June. This inaugural event was developed to support a recurrent forum for assessing the possibilities of incorporating nanoscience into the nuclear science technology suite. Winston served as a workshop organizer, in addition to Lori Braase, Idaho National Laboratory; Rob Price, DOE; Stuart Maloy, Los Alamos National Laboratory; Jeremy Busby, Oak Ridge National Laboratory; and James Buelt, Pacific Northwest National Laboratory.

The 2012 workshop was the culmination of a series of three linked events focused on convening experts in the nuclear fuel cycle with scientists recognized for their work in nanoscience applications relevant to nuclear technologies. Invited participants in- cluded scientists from DOE national laboratories, NASA, the U.S. Office of Naval Research, and the U.S. Air Force Institute of Technology, as well as academic institutions engaged in nanotechnology research. Workshop objectives included identifying productive lines of research, assessing the enhancements that could result, determining plausible approaches for conducting the research, and establishing metrics for measuring progress and determining success.

"The high hopes for nanotechnology applications in the nuclear industry must be tempered by the fact that little is currently known about the effects of the rigors of a nuclear environment on nanoscale materials," said Winston. "Research and development is needed, which must be informed by a deeper understanding of what is immediately plausible, what is not, and what are the potential benefits and research and development needs."

The workshop hosted nearly 100 scientists, engineers, and technology experts to begin exploration of these questions. Their dialogue was framed by a series of talks on current issues in both nanotechnology and nuclear science, as well as perspectives on how these two disciplines could join to bring about new innovations. Speakers included Peter B. Lyons, U.S. assistant secretary for Nuclear Energy, and Victor H. Reis, senior advisor, Office of the Under Secretary for Science, DOE. (See sidebar: 2012 NanoNuclear Workshop Presentations Available for Download.) 
The heart of the three-day program, however, was an intensive series of breakout sessions examining three broad aspects of applying nanoscale methods and materials to nuclear power challenges. These topic areas and the key discussion points were:

\section{Physics and Thermal Hydraulics:}

- Shielding of personnel or sensitive instrumentation by exploiting properties of nanoparticles or nanocomposites

- High response sensors/ discriminators comprised of nanostructured arrays or polycrystalline structures

- Exploitation of novel properties of certain nanomaterials to enhance thermal conductivity in fuel pins, improve thermal and improve the coefficient of heat transfer on surfaces

- Novel uses of fullerenes and nanoclusters in fuel design and fabrication to achieve greater burn-up conductivity of primary coolants,

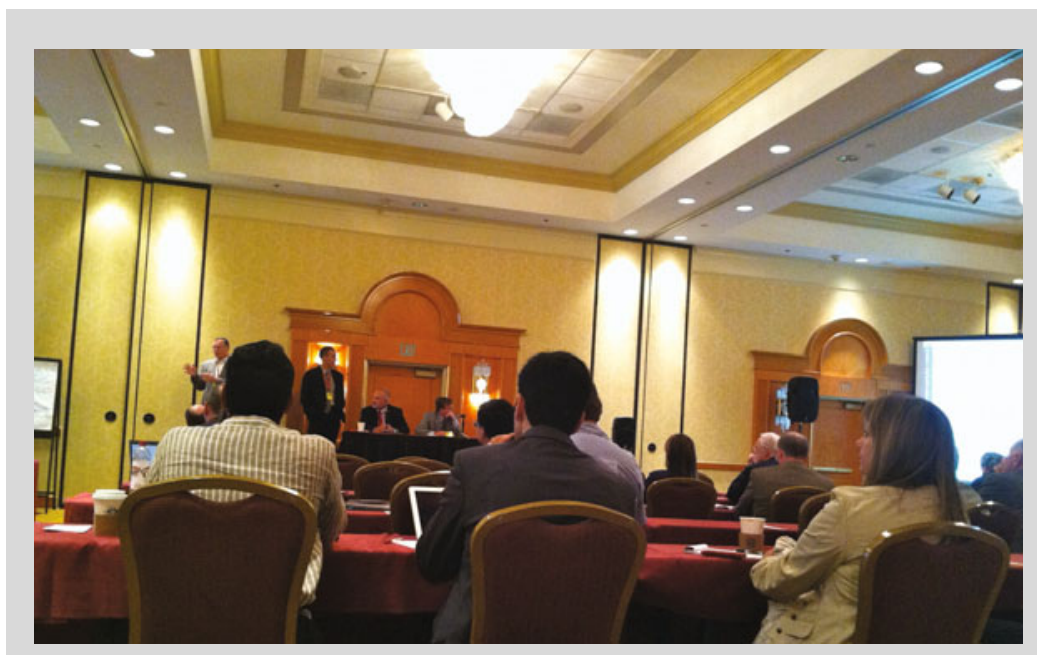

Nearly 100 scientists, engineers, and technical experts examined how nanostructured materials could be incorporated into certain nuclear reactor applications.

\section{Chemistry:}

- Separation processes for purifying uranium and rare earth ores

- Enabling economic extraction of uranium and other minerals from sea water

- Mitigating oxidation of fuel

\section{NANONUCLEAR WORKSHOP PRESENTATIONS AVAILABLE FOR DOWNLOAD}

Learn more about the possibilities of creating effective synergies between the fields of nanotechnology and nuclear science. Visit the 2012 NanoNuclear Workshop website at $h$ ttp://www.tms.org/meetings/2012/nanonuclear/post.aspx to view any or all of the following presentations made at that event:

- "Status of Nuclear Energy Programs in the United States"

Peter B. Lyons, U.S. assistant secretary for Nuclear Energy

- "United States Energy System and Innovation Needs"

Victor H. Reis, senior advisor, Office of the Under Secretary for Science,

U.S. Department of Energy

- "Nanotechnology and Nuclear: One Case Study"

Vicki Colvin, Kenneth S. Pitzer-Schlumberger Professor of Chemistry and professor, Chemical and Biomolecular Engineering, Rice University

- "Fuel Cycle Research and Development"

Kemal Pasamehmetoglu, Associate Laboratory Director-Nuclear Science

\& Technology, Idaho National Laboratory

- "Advanced Reactor Technology"

Robert Hill, Technical Director-Advanced Nuclear Energy Research and

Development, Argonne National Laboratory

- "Nanotechnology Overview"

Daniel Mittleman, professor, Department of Electrical and Computer

Engineering and faculty director, Lockheed Martin Advanced Nanotechnology Center of Excellence, Rice University

- "Mechanical Properties/Structures"

Stuart Maloy, technical staff member, Los Alamos National Laboratory

Make sure to check the website regularly to review the workshop's findings and recommendations, which will be posted before the close of 2012 at http://www.tms .org/meetings/2012/nanonuclear/home.aspx. cladding and other in-core components using specialized methods of bonding and coatings

- Developing novel approaches to fuel fabrication

- Separation of fission products

\section{Mechanical Properties:}

- Enhancing the durability of cladding and fuel

- Extending the life of structural components exposed to high neutron and gamma fluencies

- Mitigating in-service damage to key reactor components

A report summarizing the workshop findings and resulting recommendations is currently being compiled and will be available on the NanoNuclear Workshop website at http://www .tms.org/meetings/2012/nanonuclear home.aspx.

"We have clearly determined that there is significant potential for incorporating nanotechnology for improving both the safety and performance of nuclear power systems in all aspects, from the reactor core to the ancillary systems and basic structural components," said Winston. "We're now moving ahead to set priorities and lay out a coherent road map that bridges the gap from basic science to practical application. The final report will provide the foundations for beginning this process."

Lynne Robinson is a news and feature writer for TMS. 